\title{
RNA Silencing and Plant Viral Diseases
}

\author{
Ming-Bo Wang, ${ }^{1}$ Chikara Masuta, ${ }^{2}$ Neil A. Smith, ${ }^{1}$ and Hanako Shimura ${ }^{2}$ \\ ${ }^{1}$ CSIRO Division of Plant Industry, Clunies Ross Street, Canberra, ACT 2601, Australia; ${ }^{2}$ Graduate School of Agriculture, \\ Hokkaido University, Kita-ku kita 9, Nishi 9 Sapporo 060-8589, Japan
}

Submitted 26 April 2012. Accepted 29 May 2012.

\begin{abstract}
RNA silencing plays a critical role in plant resistance against viruses, with multiple silencing factors participating in antiviral defense. Both RNA and DNA viruses are targeted by the small RNA-directed RNA degradation pathway, with DNA viruses being also targeted by RNA-directed DNA methylation. To evade RNA silencing, plant viruses have evolved a variety of counter-defense mechanisms such as expressing RNA-silencing suppressors or adopting silencingresistant RNA structures. This constant defense-counter defense arms race is likely to have played a major role in defining viral host specificity and in shaping viral and possibly host genomes. Recent studies have provided evidence that RNA silencing also plays a direct role in viral disease induction in plants, with viral RNA-silencing suppressors and viral siRNAs as potentially the dominant players in viral pathogenicity. However, questions remain as to whether RNA silencing is the principal mediator of viral pathogenicity or if other RNA-silencing-independent mechanisms also account for viral disease induction. RNA silencing has been exploited as a powerful tool for engineering virus resistance in plants as well as in animals. Further understanding of the role of RNA silencing in plant-virus interactions and viral symptom induction is likely to result in novel anti-viral strategies in both plants and animals.
\end{abstract}

Viruses can infect all types of organisms and are among the most important causal agents of infectious diseases in both plants and animals. The genome structure and life cycle of viruses have been extensively studied and well understood. Viruses have relatively small genomes comprising RNA or DNA in either single- or double-stranded forms, which encode a small number of proteins to support their life cycle and transmission. They replicate only within the living cells of their host organisms using RNA-dependent RNA polymerase, DNA replicase, or reverse transcriptase encoded by their own genome. However, viroids, a subviral agent, use host-encoded RNA polymerase to replicate. Viruses, in general, have a relatively narrow host range but the mechanisms that determine such host specificities remain unclear.

Viral infections can cause a variety of disease symptoms in plants, such as stunting, mosaic patterns, yellowing, leaf rolling, ring spot, necrosis, wilting, and other developmental abnormalities (Hull 2002). Virus-induced symptoms in plants were observed and even exploited for commercial use well before viruses were known to exist. A famous example was the spectacular tulip flowers with flame-like streaks that were sold

Corresponding authors: M.-B. Wang; E-mail: ming-bo.wang@csiro.au; and C. Masuta; E-mail: masuta@res.agr.hokudai.ac.jp at extremely high prices in The Netherlands in the 17th century, leading to the phenomenon called "Tulip Mania". It was later found that this flower pattern was caused by infection with Tulip breaking virus (Dekker et al. 1993). Another interesting example was the autumnal yellow appearance of the leaves of eupatorium plants depicted a millennium ago by the Japanese Empress Koken in a poem of the earliest anthology of Japanese poetry, which is regarded as the earliest recorded plant virus disease (Saunders et al. 2003). The beautiful yellow symptoms in the plants (Fig. 1A) were actually caused by a geminivirus (Eupatorium yellow-vein virus) and its satellite DNA ( $\beta$-satellite DNA component). Closer to us, we can see similar symptoms on honeysuckle plants with bright yellow vein-clearing, caused by infection with a geminivirus (Honeysuckle yellow-vein virus) and its satellite DNA; such plants are sold as foliage varieties at garden centers. It should be noted that the satellite DNA is required for inducing these striking symptoms. These interesting stories indicate that viral symptoms are lurking next to us and raise an interesting question about the molecular mechanisms that produce these color patterns in flowers and foliage. We do not yet have a clear answer to this despite the many years of extensive research but recent studies have implicated RNA silencing as a key mediator of viral disease symptoms in plants (Pallas and Garcia 2011; Wang and Metzlaff 2005). In fact, RNA silencing has long been established as an antiviral defense mechanism in plants (Waterhouse et al. 2001). Here, we provide a brief overview of our current understanding of the involvement of RNA silencing in the two-way interaction between viruses and plants, with emphasis on viral disease induction. We also discuss the possible role of RNA silencing in the evolution of viral and host genomes.

\section{RNA SILENCING AND ITS ROLE IN PLANT-VIRUS INTERACTIONS}

RNA-silencing pathways in plants.

RNA silencing has evolved from an unexpected observation during plant transgenic studies in 1990 into a diverse field of molecular biology research today (Eamens et al. 2008). Viruses have been a critical tool in unveiling the mechanisms and biological functions of RNA silencing. In fact, studies on pathogenmediated virus resistance in plants in the early 1990s provided the first evidence that RNA is the inducer of gene silencing (Lindbo et al. 1993). Also, the RNA-directed DNA methylation (RdDM) phenomenon was first observed in a study on a viroid transgene in tobacco (Wassenegger et al. 1994). Subsequent research involving viral RNA-silencing suppressors has contributed greatly to deciphering the function of individual RNA-silencing factors in plants. 
The basic process of RNA silencing in plants is now well understood (Baulcombe 2004; Eamens et al. 2008; Meister and Tuschl 2004). Double-stranded (ds) or hairpin (hp) RNA is processed by Dicer-like (DCL) proteins into 21- to 24-nucleotide (nt) small RNAs (sRNAs), which are loaded to members of the Argonaute (AGO) family to form an RNA-induced silencing complex (RISC). RISC then uses the sRNAs as guide to direct RNA degradation, translational repression, or DNA methylation of homologous target genes. There are three basic RNA-silencing pathways in plants: namely, the micro (mi) RNA pathway, the small interfering (si)RNA-directed RNA degradation pathway, and the RdDM pathway. In the miRNA pathway, imperfect short hpRNA formed between the complementary regions of a primary miRNA transcript is processed in the nucleus by DCL1, one of the four DCL proteins in Arabidopsis, into a single 21- to 24-nt miRNA. Several other factors, including the zinc-finger protein SERRATE and the dsRNA-binding protein DRB1 or HYL1, are also involved in miRNA biogenesis. miRNAs play a critical role in the control of plant development by repressing or fine-tuning the expression of regulatory genes such as transcription factors. Unlike animal miRNAs which bind 3' untranslated regions (UTR) and function through translational repression, plant miRNAs target primarily the coding regions of mRNA and function predominantly through RNA cleavage, although recent studies suggest that plant miRNAs can also act through translational repression (Brodersen et al. 2008). In the siRNA-directed RNA degradation pathway, endogenous or exogenous long dsRNA or hpRNA is processed by DCL4 and DCL2 into 21- and 22-nt siRNAs, respectively. Like miRNAs, these siRNAs bind AGO1 to form RISC and guide RISC to cleave single-stranded (ss) RNAs. The endogenous long dsRNA precursor of these siRNAs is synthesized by RNA-dependent RNA polymerase 6 (RDR6), one of the six RDR in Arabidopsis, using ssRNA as template. The endogenous siRNAs, known as trans-acting (ta)-siRNAs, play an important role in plant development and stress response. However, the siRNA-directed RNA degradation pathway appears to function predominantly in plant antiviral defense.
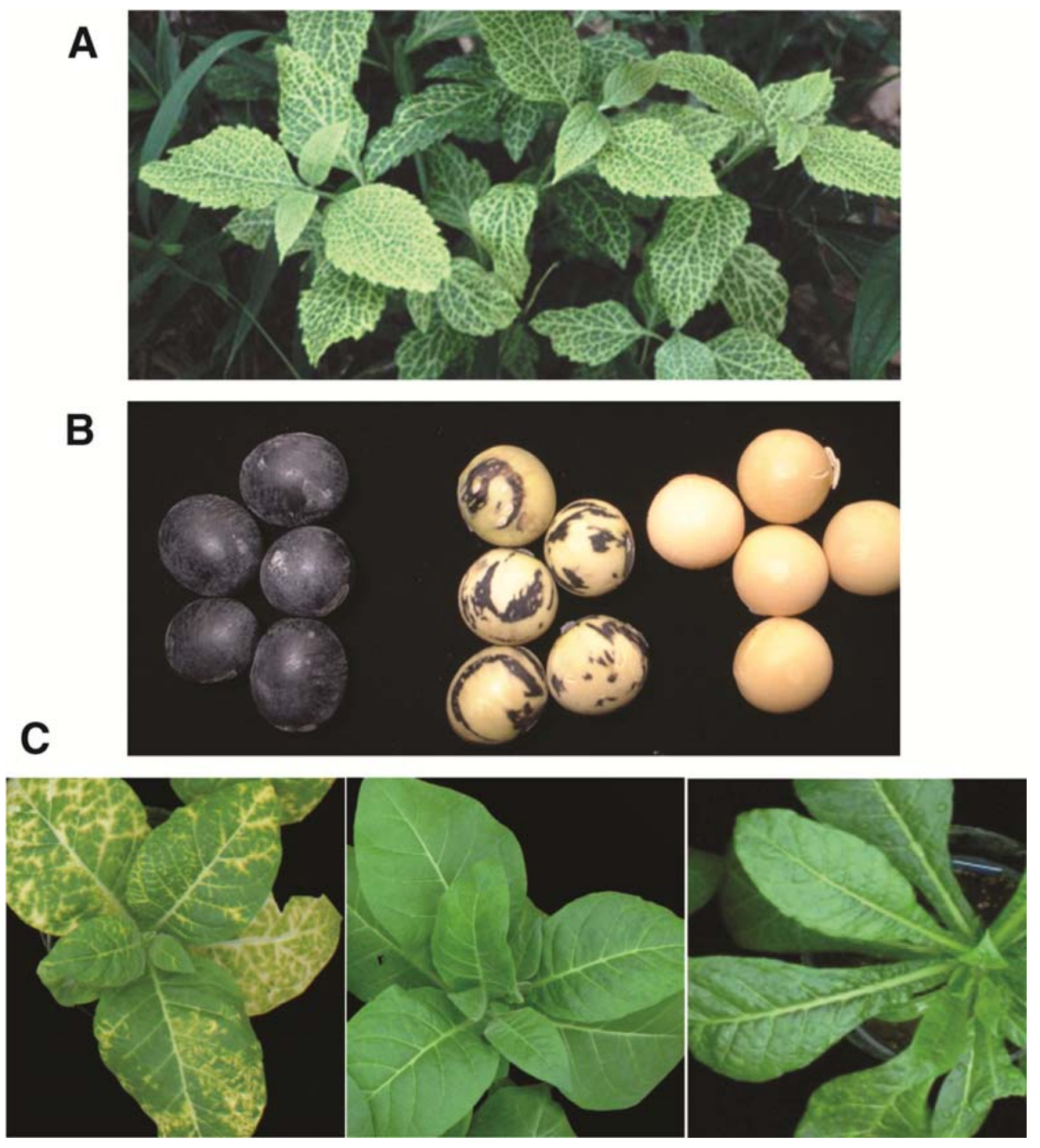

Fig. 1. Examples of viral disease symptoms and the involvement of RNA silencing in disease induction. A, Eupatorium yellow-vein virus-infected eupatorium plants exhibiting the typical yellow-vein symptoms. The disease was induced by a geminivirus and its satellite. B, Mottling symptoms on soybean seed infected with Cucumber mosaic virus soybean strain (CMV-Sj). The virus-infected soybean seed were placed between healthy yellow (right) and black (left) soybean seed. C, Nicotiana plants infected with CMV + Y satellite RNA (Y-sat). On the left is a wild-type Nicotiana tabacum plant showing typical bright yellow symptoms; in the middle is an N. tabacum plant transformed with a modified version of the CHLI gene that is resistant to Y-sat small interfering (si)RNA-directed silencing, preventing the plant from developing the yellowing symptoms; and on the right is an N. debneyi plant in which the Y-sat siRNAtargeted region of the CHLI gene contains a mismatched nucleotide preventing effective silencing of CHLI and, hence, the yellowing symptoms. 
The RdDM pathway is unique to plants and plays a key role in silencing transposons and repetitive DNA elements to maintain genome stability and integrity (Haag and Pikaard 2011; Matzke et al. 2009). As discussed below, RdDM appears to play a role in plant defense against DNA viruses. RdDM is directed by 24-nt siRNAs, which are processed by DCL3 from dsRNA synthesized by the plant-specific DNA-dependent RNA polymerase IV (Pol IV) and RDR2. The molecular details of RdDM have yet to be fully understood. In the current model, 24-nt siRNAs form RISC with AGO4 which, in turn, interacts with nascent transcript produced by another plant-specific RNA polymerase, Pol V, to recruit methylation factors such as DRM2, inducing de novo cytosine methylation in the target DNA.

RNA silencing as an antiviral defense mechanism in plants.

The majority of plant viruses are positive-sense RNA viruses, which have either ss- or dsRNA genomes and depend on viral RNA-dependent RNA polymerase (replicase) for multiplication; minority viruses with DNA genomes belong to just a few families. On the other hand, most animal viruses have a dsDNA or ssRNA genome. A key difference between RNA and DNA viruses lies in the different subcellular locations of their replication. dsDNA viruses can use all of the necessary factors in the DNA replication machinery of host cells and, thus, tend to multiply in the nucleus of the infected cells. RNA viruses do not need the cellular DNA synthesis machinery and, therefore, normally replicate in the cytoplasm of the infected cells.
RNA silencing is not the only antiviral defense mechanism in plants. Viruses, like fungal and bacterial pathogens, can also be subject to innate immune responses conferred by host-encoded disease resistance genes. Indeed, natural virus resistance genes are continuing to be sought for use in breeding for durable virus resistance in crop plants (Maule et al. 2007). Plants have evolved a variety of immune systems, which include pathogen-associated molecular pattern-triggered immunity (PTI) and effector-triggered immunity (ETI). When pathogen effectors overcome PTI, plants employ resistance $(\mathrm{R})$ proteins to activate ETI, where pathogen effectors are recognized as avirulence (Avr) factors by $\mathrm{R}$ proteins. $R$-gene-mediated resistance is often accompanied by a hypersensitive response (HR), which is usually identified as a distinctive symptom of necrotic local lesion. The tobacco $N$ gene against Tobacco mosaic virus (TMV) was the first-identified $R$ gene conferring resistance to a virus (Whitham et al. 1994), and the Avr gene of TMV was found to be the replicase gene. HR functions to restrict the virus in the infection site but sometimes veinal necrosis or even systemic lethal necrosis occurs when HR fails to fully restrict the invaded virus, which can be mistakenly regarded as normal viral symptoms. For example, Turnip mosaic virus (TuMV) induces lethal necrosis in some crucifer plants such as Arabidopsis (Kaneko et al. 2004) and Brassica napus (Jenner et al. 2003 ) in response to the corresponding $R$ genes. In this case, the necrotic symptoms are actually induced by the host resistance response.

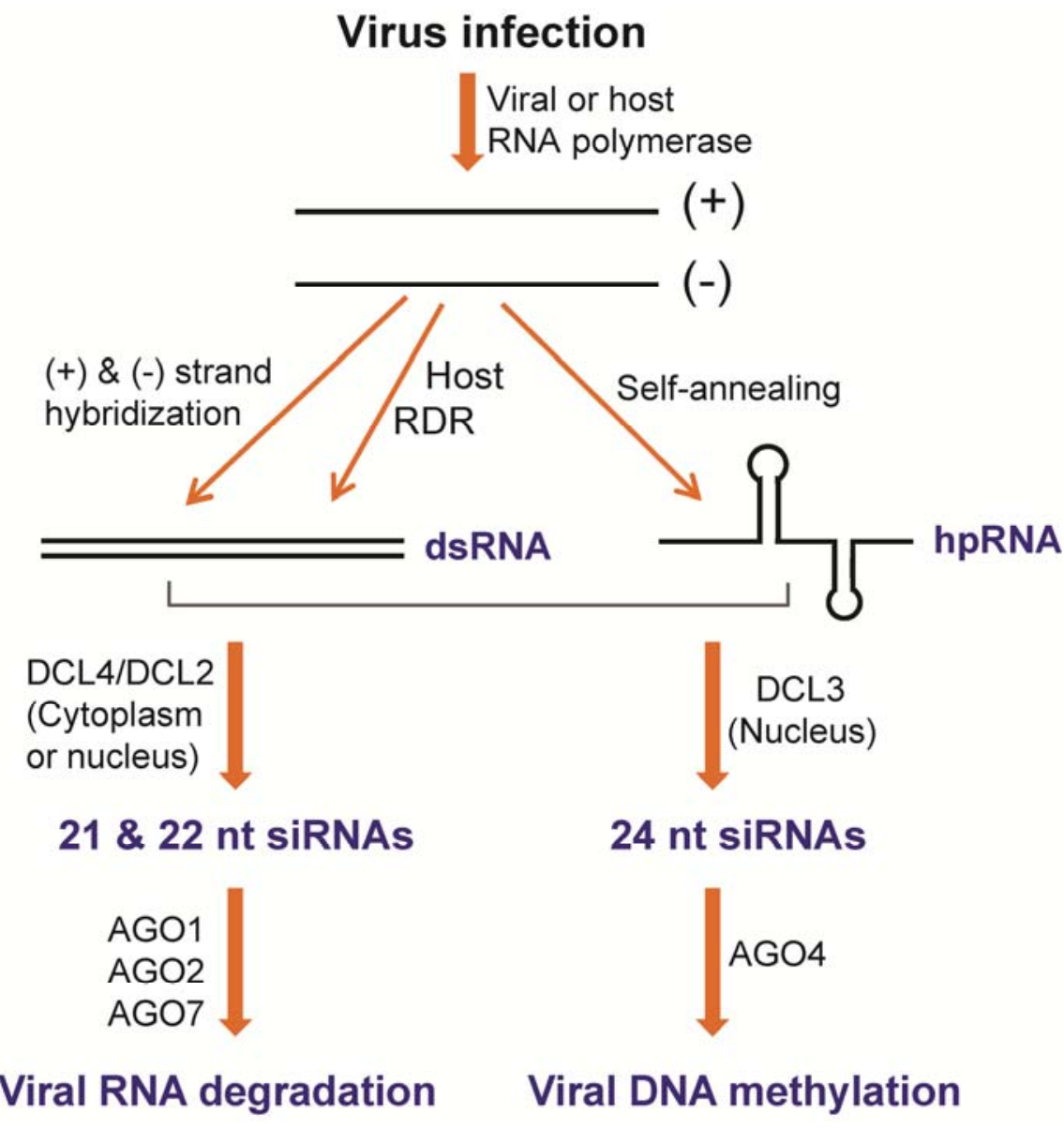

Fig. 2. Possible viral small interfering (si)RNA biogenesis pathways. Viral double-stranded (ds)RNA or hairpin (hp)RNA is formed by direct hybridization between plus (+) and minus (-) strand replicative intermediates, by host RNA-dependent RNA polymerase (RDR)-catalyzed synthesis from single-stranded viral RNA, or by self-annealing of complementary regions within single-stranded viral RNA. The dsRNA is processed by Dicer-like (DCL) 4 and DCL2 proteins in the cytoplasm (and perhaps the nucleus) into 21- and 22-nucleotide (nt) siRNAs that are loaded onto Argonaute (AGO)1, AGO2, or AGO7 to direct cleavage of viral RNAs. dsRNA or hpRNA in the nucleus is processed by DCL3 into 24-nt siRNAs that are loaded to AGO4 to direct cytosine methylation in the viral DNA genome via the RNA-directed DNA methylation pathway. 
However, unlike bacterial and fungal pathogens, viral genomes replicate within the host cells and, hence, the RNA-silencing pathways play a critical role in anti-viral defense. The siRNA pathway has been well established to be a natural antiviral defense mechanism in plants. Infection of plants with all viruses and subviral agents (viroids, satellites, and defective interfering RNAs) is associated with the accumulation of viral siRNAs which, in turn, can direct silencing against the viral genome (Ruiz-Ferrer and Voinnet 2009; Voinnet 2005). Thus, viruses are both inducers and targets of RNA silencing. The biogenesis of viral siRNAs has not been fully understood but several possible pathways are summarized in Figure 2. It was initially thought that viral siRNAs are derived from dsRNA formed between positive and negative strands of viral RNAs generated by viral or host RNA polymerase during viral replication. It has also been proposed that siRNAs of some viruses are processed from internal hairpin-loop structures formed within ss viral RNAs (Moissiard and Voinnet 2006; Molnár et al. 2005). However, more recent studies have shown that hostencoded RDR are required for producing the bulk of viral siRNAs from some RNA viruses, suggesting that the biogenesis of viral siRNA may resemble that of endogenous siRNA and depends on host RDR for dsRNA formation (Diaz-Pendon et al. 2007; Donaire et al. 2008; Garcia-Ruiz et al. 2010; Qi et al. 2009; Wang et al. 2010). Three RDR in Arabidopsis have been functionally characterized. RDR6 is involved in the tasiRNA pathway, and RDR2 is required for the production of 24-nt siRNAs associated with RdDM. Unlike RDR2 and RDR6, RDR1 has not been found to play a direct role in endogenous siRNA biogenesis, although a recent study has suggested that it is functionally antagonistic to RDR6 and represses RDR6-mediated RNA silencing in Nicotiana plants (Ying et al. 2010). In contrast, RDR1 appears to play a dominant role in antiviral silencing with RDR6 being also required (Qu 2010). However, basal levels of viral siRNAs are often present in the Arabidopsis rdrl rdr2 rdr6 triple mutant, suggesting that not all viral dsRNAs are synthesized by host RDR (Garcia-Ruiz et al. 2010). It is possible that the other two scenarios also contribute to viral siRNA biogenesis.

Infection of plants with RNA viruses and subviral RNAs is associated with predominantly 21- and 22-nt siRNAs, processed by DCL4 and DCL2, respectively (Ding and Voinnett 2007). These two DCL proteins therefore play an essential role in plant defense against RNA viruses. DCL4 plays a more dominant role than DCL2 in antiviral defense, because 21-nt siRNAs are usually more abundant than 22-nt siRNAs during RNA virus infection, and loss-of-function mutation in DCL4 has a stronger impact on viral resistance than that in DCL2. This functional predominance of DCL4 over DCL2 could also be partly due to the more potent antiviral silencing effect of the 21-nt siRNAs than the 22-nt species (Wang et al. 2011). These 21- and 22-nt viral siRNAs bind to AGO proteins and direct silencing of viral RNAs. AGO1 is the dominant AGO in viral siRNA-directed antiviral defense. However, AGO7 and, more recently, AGO2 have also been found to play a role in anti-viral silencing (Harvey et al. 2011; Jaubert et al. 2011; Qu et al. 2008; Wang et al. 2011). It has been proposed that AGO1 forms the first layer of antiviral defense while the other two AGO proteins act as a second layer (Harvey et al. 2011; Qu et al. 2008).

DCL3 only seems to play a minor role in plant resistance to RNA viruses, as suggested by the normally low levels of 24-nt siRNAs associated with RNA virus infection and the loss-offunction mutation in DCL3 having no major impact on viral accumulation. However, DCL3 has a major function in plant resistance to DNA viruses. In contrast to RNA viruses, all three size classes of siRNAs accumulate in DNA virus-infected plants, with a large proportion being the 24-nt class that is pro- cessed by DCL3 (Akbergenov et al. 2006; Blevins et al. 2006; Moissiard and Voinnet 2006). Studies on germiniviruses showed that the 21- and 22-nt siRNAs correspond to the coding regions of the viral genome capable of directing RNA cleavage, while the 24-nt siRNAs are derived mainly from intergenic regions that can direct cytosine methylation in these viral genome regions (Rodríguez-Negrete et al. 2009; Yadav and Chattopadhyay 2011). The degree of methylation in intergenic regions is inversely correlated with the levels of viral DNA and the severity of symptoms, suggesting that the RdDM pathway is involved in plant resistance to DNA viruses. Consistent with this, it has also been shown that host recovery from the DNA virus requires AGO4 (Raja et al. 2008), the key downstream component of RdDM. However, the presence of 21- to 22-nt siRNAs in DNA virus-infected plants indicates that siRNAdirected RNA degradation also contributes to plant defense against DNA viruses.

DCL1 does not appear to have a direct role in siRNA biogenesis from RNA viruses, although it seems to contribute to the biogenesis of 21-nt siRNAs from DNA viruses (Blevins et al. 2006). Recent studies indicate that DCL1 plays an indirect role in antiviral silencing by negatively regulating the expression of DCL4 and DCL3 in A. thaliana; DCL4 and DCL3 expression was upregulated in the $d c l l$ mutant, which was associated with reduced virus accumulation ( $\mathrm{Qu}$ et al. 2008). One suggested explanation was that the expression of DCL3 and DCL4 might be regulated by transcriptional factors that are negatively regulated by microRNAs. However, the biological significance of this possible DCL1-mediated negative control of antiviral silencing remains unclear. Another possible involvement of DCL1 in antiviral defense could come from its general function in miRNA biogenesis. Both AGO1 and AGO2, key components of the viral siRNA-RISC, are negatively regulated by miRNAs that are processed by DCL1. A recent study indicates that viral infection induces miR168 expression which, in turn, reduces AGO1 protein accumulation (Várallyay et al. 2010), thus minimizing antiviral silencing.

A recent bioinformatic study suggests that plant miRNAs can potentially target viral genomes due to sequence homology and have a strong potential for antiviral activity (Perez-Quintero et al. 2010). However, the existence of abundant siRNAs derived from the virus genome itself makes it less likely that host sRNAs play a critical role in plant antiviral defense. Furthermore, recombination and mutation can occur rapidly in RNA viral genome, allowing RNA viruses to potentially escape from host sRNA-directed silencing. In this respect, however, host sRNAs could play an important role in the initial establishment of viral infection in a particular host plant. Interestingly, $2 b$, the RNA-silencing suppressor encoded by cucumoviruses, has been shown to promote RNA recombination (Asaoka et al. 2010; Shi et al. 2008), which could imply that $2 \mathrm{~b}$ might play a role in minimizing the targeting of viral RNA by host sRNAs. Unlike plants, host miRNAs in mammalian cells play a critical role in antiviral defense. For instance, human-encoded miRNAs have been shown to target human immunodeficiency virus (HIV) genes to suppress HIV replication (Ahluwalia et al. 2008). A cellular miRNA can effectively restrict the accumulation of the retrovirus primate foamy virus (PFV-1) in human cells (Lecellier et al. 2005). A liver-specific miRNA, on the other hand, has been shown to positively regulate the replication of hepatitis $\mathrm{C}$ virus (Jopling et al. 2005). These examples indicate that host miRNAs can modulate viral infections in both positive and negative fashion in mammalian cells.

\section{Viral counter-defense mechanisms.}

Viruses have evolved a number of strategies to overcome the RNA-silencing-mediated host defense mechanism (Burgyán and 
Havelda 2011; Ding and Voinnet 2007; Hohn and Vazquez 2011; Roth et al. 2004). Almost all plant viruses encode multifunctional proteins which, in addition to their functions in viral life cycles such as viral replication, encapsidation, or movement, interfere with the host RNA-silencing pathways. These proteins, known as viral suppressors of RNA silencing (VSR), function to inhibit RNA silencing through a diverse mode of action. A dominant mode of action by VSR is to bind long dsRNA or siRNA duplexes to inhibit siRNA biogenesis or RISC formation (Lakatos et al. 2006; Mérai et al. 2006). Another known mode of action by VSR is to physically interact with AGO1 to block siRNA loading, inhibit slicing activity, or cause degradation of the AGO1 protein (Azevedo et al. 2010; Baumberger et al. 2007; Bortolamiol et al. 2007; Zhang et al. 2006). VSR can also function by interacting with siRNA biogenesis machineries such as the dsRNA-binding protein DRB4 inhibiting dsRNA processing by DCL4 (Haas et al. 2008). HEN1 functions downstream of the plant sRNA biogenesis pathways to methylate the 2'-hydroxyl group at the $3^{\prime}$ termini of siRNAs and miRNAs, which function to stabilize the sRNAs. VSR interfere with HEN1-mediated methylation of viral siRNAs (Ebhardt et al. 2005; Lozsa et al. 2008; Yu et al. 2006), and this could represent another general strategy of VSR to counteract anti-viral RNA silencing. A recent study shows that some VSR, such as the tombusvirus P19, inhibit antiviral RNA silencing by inducing the expression of miR168, an miRNA that targets AGO1 mRNA, resulting in reduced accumulation of AGO1 protein (Várallyay et al. 2010). In addition to suppression of the RNA degradation pathway, VSR encoded by DNA viruses have been shown to inhibit transcriptional gene silencing (TGS) in plants by reducing DNA methylation (Buchmann et al. 2009). Two recent studies provide insights into how DNA virus-encoded VSR inhibit DNA methylation and TGS in the host. In one study, the $\beta C 1$ protein encoded by the $\beta$ satellite of Tomato yellow leaf curl China virus was shown to interact with and inhibit the activity of S-adenosyl homocysteine hydrolase, a methyl cycle enzyme required for cytosine methylation (Yang et al. 2011). In a separate study, the $\mathrm{C} 2$ protein of Beet severe curly top virus is shown to attenuate the $26 \mathrm{~S}$ proteasomemediated degradation of S-adenosyl-methionine decarboxylase through physical interaction, resulting in inhibition of DNA methylation and, hence, TGS on the viral genome (Zhang et al. 2011). These studies suggest that DNA virus-encoded VSR inhibit RdDM in host cells to minimize viral genome methylation, providing further evidence that the RdDM pathway plays an important role in plant defense against DNA viruses. The $2 \mathrm{~b}$ protein from Cucumber mosaic virus (CMV), an RNA cucumovirus, also interferes with the RdDM pathway (Duan et al. 2012). The diverse mode of action by VSR from different viruses suggests that they have evolved separately to suit specific virus-host interactions.

Viroids are subviral agents that have small (120- to 475-nt) RNA genomes and do not encode functional proteins. To avoid antiviral silencing by the host, viroids appear to have evolved alternative strategies by forming degradation-resistant secondary RNA structure (Itaya et al. 2007; Wang et al. 2004) and by replicating in the nucleus or chloroplast away from the cytoplasm where RISC is assumed to predominantly function. Similar to viroids, satellite RNAs and defective-interfering viral RNAs are also shown to adopt secondary structures that are resistant to siRNA-mediated degradation (Szittya et al. 2002; Wang et al. 2004). Some viruses may also have evolved RNA structure-based strategies to evade RNA silencing. siRNAs from infecting Cauliflower mosaic virus (CaMV) are almost entirely derived from its 35S leader sequence (Blevins et al. 2011; Moissiard and Voinnet 2006). This 600-nt leader sequence is highly structured and resistant to siRNA-directed degradation and, consequently, these siRNAs do not appear to have an impact on CaMV accumulation (Blevins et al. 2011). Furthermore, it is suggested that this leader sequence functions to sequester silencing machineries to reduce siRNA biogenesis from other part of the CaMV genome, thereby minimizing RNA silencing against the virus (Blevins et al. 2011).

\section{RNA silencing as a mediator of viral diseases in plants.}

Before RNA silencing was known, viral disease symptoms were thought to be a consequence of direct interaction between viral and host essential proteins. However, there are only a few cases where a viral protein was found to affect the intrinsic function of a host protein through direct or indirect binding. In one example, the P2 protein of Rice dwarf virus (RDV) was demonstrated to have a direct interaction with rice ent-kaurene oxidases (Zhu et al. 2005) that play a role in the biosynthesis of a phytohormone, gibberellin. Thus, it is reasonable to postulate that this interaction leads to reduced accumulation of the hormone resulting in stunting of the infected rice plants. Another recent study (Inaba et al. 2011) provided evidence that the $2 \mathrm{~b}$ protein of CMV can bind to an Arabidopsis catalase (CAT3) that is important in scavenging cellular hydrogen peroxide, resulting in the induction of specific necrosis in the infected leaves of Arabidopsis. Many attempts have been made to find host factors that interact with viral proteins, resulting in viral pathogenicity. For example, more than 10 host factors required for multiplication of tobamoviruses have been identified (Ishibashi et al. 2010); these factors will certainly play a role in viral pathogenicity as well as viral multiplication. However, it is usually difficult to establish a link between virushost protein interactions and observed symptoms unless the host protein has an essential physiological function related to the virus-caused phenotype.

\section{Role of VSR in symptom induction.}

VSR are often found to be a primary pathogenicity determinant of viruses. Viral disease symptoms will undoubtedly be affected by the level of viral accumulation in infected tissues which, in turn, would be affected by the arms race between host RNA silencing and the activity of VSR. This is perhaps well illustrated by the mosaic phenotypes in virus-infected leaves with the appearance of dark-green zones, where viral accumulation is diminished, compared with the light-green zones due to host RNA-silencing-mediated resistance to subsequent viral invasion (Moore et al. 2001; Hirai et al. 2008). However, recent studies suggest that VSR may contribute to viral disease induction primarily by interfering with the host miRNA pathway that is required for normal plant development (Fig. 3).

Plant miRNAs have been demonstrated to negatively regulate mRNAs encoding important regulatory factors in various developmental processes, nutrient homeostasis, stress responses, and defense against pathogens (Carrington and Ambros 2003; Pasquinelli and Ruvkun 2002; Zhang et al. 2010). Therefore, it is conceivable that VSR can cause developmental abnormalities in processes such as cell division, leaf formation, and flower development by affecting the expression and function of miRNAs, thus resulting in disease symptoms (Kasschau et al. 2003). Consistent with this, transgenic plants expressing VSR often showed viral symptom-like phenotypes (Chapman et al. 2004; Chellappan et al. 2005; Jay et al. 2011). VSR proteins usually have a basic, positively charged domain, which directly interacts with sRNAs. An example of this is the tombusvirusencoded P19, which binds 21-nt siRNA or miRNA duplexes preventing the formation of RISC (Lakatos et al. 2006). Unrelated VSR from multiple viruses have also been shown to affect miRNA accumulation in plants. Some VSR were shown 
to reduce host miRNA accumulation while others increase the accumulation of miRNAs. In contrast, many animal viruses have been reported to downregulate the expression of host miRNAs (Du et al. 2011). A recent study showed that Rice stripe virus (RSV) and RDV infections differentially affected rice sRNA profiles, and that RSV but not RDV induced the expression of novel miRNAs from conserved miRNA precursors (Du et al. 2011). RSV infection significantly enhanced the levels of rice DCL and AGO proteins, which are essential players in the host RNA-silencing machinery. Thus, these observations suggest that VSR and viral infection induce major changes in the entire RNA-silencing pathway, including the miRNA pathway in plants, and that these VSR-induced changes play an important role in viral disease induction.

Recent studies have demonstrated that plant miRNAs target and negatively regulate plant nucleotide-binding leucine-rich repeat defense genes ( $R$ genes) by inducing the production of phased siRNAs against these $R$ genes, and this miRNA-mediated regulation is inhibited upon viral or bacterial infection (Pignatta et al. 2012; Zhai et al. 2011). Unregulated overexpression of $R$ genes can trigger unwanted autoimmunity and result in inhibition of plant growth and sometimes lethal necrosis. Therefore, it is possible that some viral symptoms are a combined result of the general effect of VSR on the plant miRNA pathway and their specific effect on $R$-gene-mediated defense response.

It is also worth noting here that there exists a direct interaction between $R$-gene-mediated defense and VSR which appears independent of the host RNA-silencing pathways. For example, the CMV 2b VSR was found to inhibit salicylic-acid-mediated defense response (Ji and Ding 2001) whereas the HC-Pro VSR of Potato virus $Y$ was shown to induce defense responses (Shams-Bakhsh et al. 2007). These observations indicate that some VSR are recognized by the host defense mechanism to induce disease resistance. A well-established example of such host recognition of VSR comes from the coat protein gene of Turnip crinkle virus (TCV), which is a VSR but also serves as the TCV Avr gene to induce $R$ gene (HRT)-mediated resistance (Choi et al. 2004).

In addition to the miRNA pathway, VSR can cause phenotypic changes in host plants by affecting the siRNA-mediated RNA degradation pathway. There is a petunia variety called

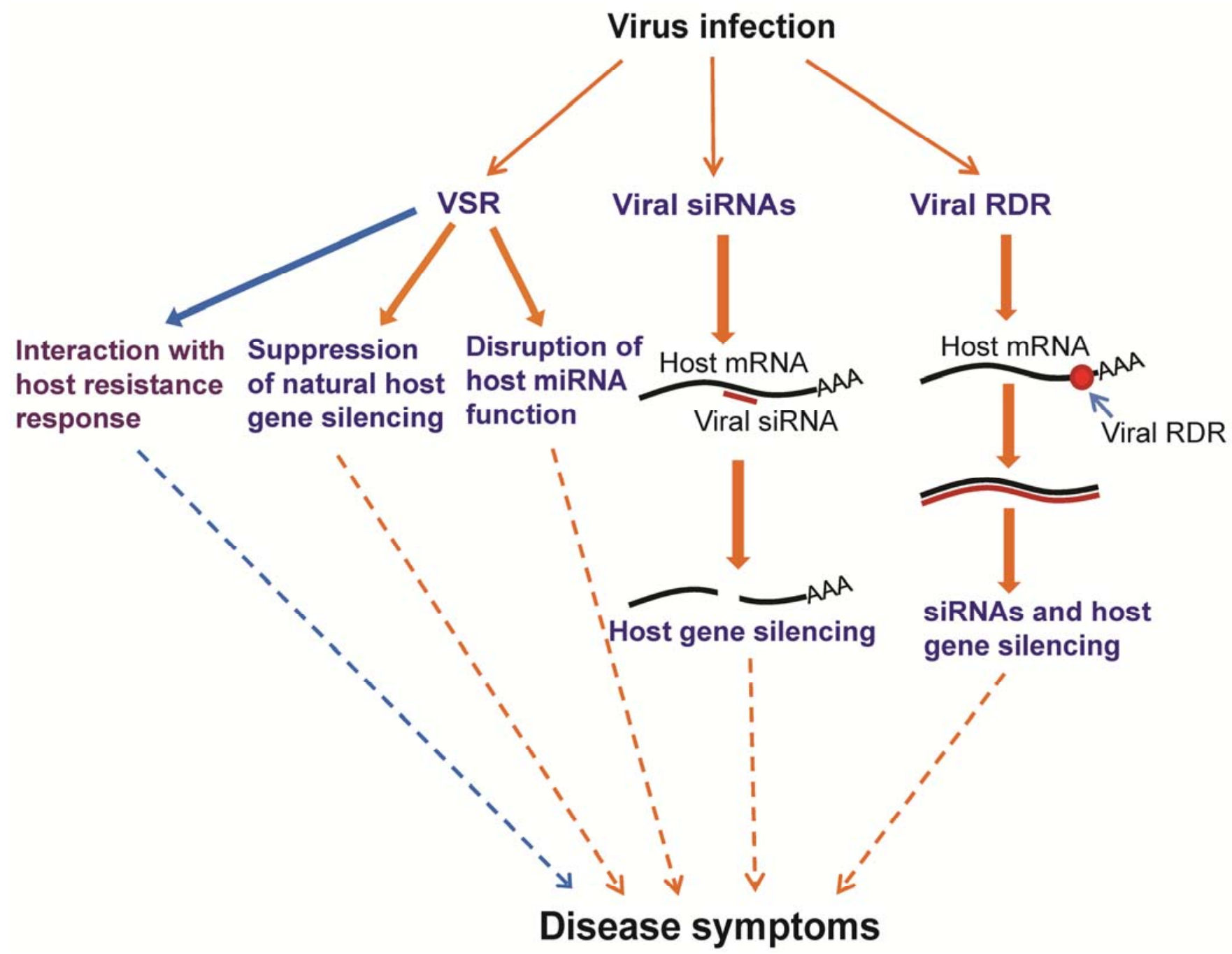

Fig. 3. Hypothetical model for RNA-silencing-mediated viral pathogenicity in plants. Viral suppressors of RNA silencing (VSR) interfere with host micro (mi)RNA function, causing developmental defects or disease symptoms in the host plants. VSR can repress naturally occurring silencing of host genes, resulting in phenotypic changes such as mottling of soybean seed coat. Alternatively, viral small interfering (si)RNAs can direct silencing of host genes due to fortuitous sequence homology between the viral genome and host genes, causing disease symptoms. Host gene silencing could also be induced by viral RNA-dependent RNA polymerase (RDR)-mediated double-stranded RNA synthesis of host mRNA due to existence of sequence motifs in the mRNA that resemble viral replication origin. In addition to these RNA silencing-based pathways, VSR can function as avirulence proteins to trigger resistance genemediated defense response (blue arrow), which could also result in viral-like symptoms. 
'Red Star' whose petals lack pigmentation along the veins and, thus, have a star-type color pattern. This lack of pigmentation is due to reduced chalcone synthase $(C H S)$ mRNA levels caused by natural RNA silencing, as demonstrated by the accumulation of $C H S$ siRNAs in the white but not the red sectors of the flower. When the Red Star plants are infected with a CMV virus, the $C H S$ mRNA level in the white sectors increases significantly and all white sectors turn red (Koseki et al. 2005). Another similar example is the mottling seed coat phenotype in soybean plants infected by viruses such as CMV and Soybean mosaic virus, which was demonstrated to be also caused by VSR-mediated reversal of natural silencing of the CHS gene that occurs in uninfected plants with the $I$ allele (Senda et al. 2004) (Fig. 1B). These observations indicate that VSR can modulate plant phenotypes or cause symptoms by inhibiting naturally occurring silencing of host genes (Fig. 3).

\section{Viral siRNAs as a direct inducer of symptoms: An example from CMV Y satellite RNA.}

Infection of plants with viruses and subviral agents is associated with the accumulation of siRNAs from the whole regions of the viral genome. It can be expected that some of these viral siRNAs would share sequence identity (or complementarity) with certain host genes and, thus, have the potential to cause silencing of the host genes. Viral siRNAs can silence host genes in several ways. siRNAs with high levels of sequence complementarity to a host gene could induce cleavage of the host mRNA, whereas those with partial complementarity could induce translational inhibition. siRNAs having high degrees of sequence identity with host gene promoters could induce cytosine methylation of the promoter through the RdDM pathway, potentially leading to transcriptional inactivation of host gene promoters. Furthermore, viral siRNA could silence host genes indirectly by initiating RDR6-mediated synthesis of secondary dsRNA of the gene, in a way similar to the biogenesis of tasiRNAs (Eamens et al. 2008). It is also conceivable that some host mRNA sequences may contain motifs that can be recognized by viral RDR to initiate dsRNA synthesis, resulting in silencing of the mRNA (Fig. 3). Such viral siRNA-directed silencing of host genes can result in developmental defects or symptoms in the host plants (Fig. 3). The first demonstration of such viral siRNA-mediated viral symptoms came from two independent and simultaneously published studies on CMV Y satellite RNA (Y-sat) (Shimura et al. 2011; Smith et al. 2011). Both articles demonstrated that the bright yellowing symptoms (Fig. 1C) on tobacco plants infected with CMV Y-sat were due to silencing of the chlorophyll biosynthetic gene ChlI directed by Y-sat-derived sRNAs. The 369-nt Y-sat genome has a 22-nt sequence region complementary to the ChlI mRNA, which may have been accidentally acquired by Y-sat during its evolution in the host Nicotiana spp. siRNAs derived from the 22-nt region of Y-sat function as a guide to direct cleavage of the cellular ChlI mRNA, eventually inducing the bright yellow symptoms observed in CMV Y-sat-infected plants. Plants expressing a silencing-resistant variant of the ChlI mRNA, or infected with a mutant Y-sat, in which the 22-nt complementary regions are modified, no longer develop the yellowing symptoms upon CMV Y-sat infection (Fig. 1C). These observations provide evidence that the previously observed host species specificity of satellite-RNA-mediated disease symptoms is due to sequence variation in the host gene or satellite RNA genome.

siRNAs derived from another subviral agent, viroids, have also been implicated in the viroid symptom induction, although target genes of viroid siRNAs have yet to be discovered (Diermann et al. 2010; Gómez et al. 2008; Wang et al. 2004). As a possible alternative to the siRNA-mediated model, it was shown that viroid infection downregulates the level of miR319 which targets the TCP (TB1, CYC, and PCF) family of transcription factors required for leaf development in tomato (Diermann et al. 2010). This suggests that there is a possible link between endogenous miRNA expression and viroidinduced symptoms.

Recent studies using sRNA sequencing and bioinformatic analyses showed that siRNAs derived from plant viruses can also target host genes for silencing, which suggests that viral siRNA-directed host gene silencing may also play a role in disease induction by plant viruses. siRNAs derived from the $\mathrm{Cg}$ strain of TMV (TMV-Cg) have recently been shown to potentially target at least two host genes, the cleavage and polyadenylation specificity factor (CPSF30) and the translocon-associated protein $\alpha(T R A P \alpha)$; siRNA-mediated specific cleavage of these mRNAs was actually verified by $5^{\prime}$ rapid amplification of cDNA ends assays (Qi et al. 2009). Earlier work also showed that a number of siRNAs derived from CaMV have near-perfect sequence complementarity to Arabidopsis transcripts and, therefore, have the potential to direct silencing of these genes in infected plants (Moissiard and Voinnet 2006). However, in these studies, the authors did not go further to demonstrate the possible link between viral siRNA-induced host gene silencing and viral pathogenicity leading to symptoms.

Unlike plant viruses, the replication of animal viruses does not seem to be associated with siRNA production. However, many mammalian viruses encode miRNAs that can inhibit the expression of host-encoded genes such as host immune system genes, resulting in physiological effects in favor of their infection (Cullen 2009; Grundhoff and Sullivan 2011; Sullivan et al. 2005). For example, Kaposi's-sarcoma-associate herpes virus (KSHV) encodes miR-K12-11, which shares significant sequence homology with cellular miR-155 and targets common cellular mRNAs with roles in cell growth, resulting in the induction of KSHV-positive B-cell tumors in infected patients (Gottwein and Cullen 2008; Gottwein et al. 2007). Another interesting example is human cytomegarovirus, which encodes miRNAs such as miR-UL112 and miR-US25-1 to regulate cellular processes. miR-UL112 downregulates cellular stressinduced ligand proteins such as MICB for recognition by the natural killer (NK) cell so that infected cells can escape from NK cell killing in favor of viral infection (Stern-Ginossar et al. 2007). miR-US25-1 was shown by RISC/miRNA pull-down to bind target sites primarily within $5^{\prime}$ UTR, mediating significant reduction in gene expression involved in cell cycle control to prevent apoptosis (Grey et al. 2010). However, like siRNAs from plant viruses, more evidence is required to confirm a direct involvement of viral miRNA-mediated host gene silencing in disease development in animals.

\section{RNA SILENCING AS POTENTIAL MEDIATOR OF VIRUS AND HOST GENOME EVOLUTION}

\section{Host RNA-silencing forces the evolution of viral genome structures.}

It has become clear that RNA silencing is an important selective force in shaping plant viral genomes. To avoid viral siRNA-directed silencing of their genome, plant viral and subviral genomes have evolved the capacity to encode VSR or to form silencing-resistant secondary structures. In addition, the selective pressure of being potentially targeted by host-encoded sRNAs, and the developing ability to target host genes with their own siRNAs or miRNAs, may have also contributed to viral genome evolution. Single-nucleotide polymorphisms that prevent viral siRNA or miRNA-directed "lethal" silencing of certain host genes might be under strong positive selection in the viral genome. Similarly, sequence variations in the viral genome that prevent viruses from being efficiently targeted by 
specific host-encoded sRNAs may also be positively selected during viral genome evolution. Such sRNA-mediated selection could partly account for some of the virus-host specificities.

Viral replications have a relatively high error rate, and viruses often exist as quasispecies (mixtures of minor sequence variants), and this rapid sequence evolution may have served to minimize host sRNA-directed silencing facilitating viral infection in a specific host-virus interaction. The host antiviral RNA silencing may also account for the lack of sequence homology between satellites and their helper viruses, which is presumably to avoid silencing of helper viral genome by satellite-derived siRNAs which usually accumulate at very high abundance in infected host tissue.

\section{Viruses use RNA silencing to impact host genome.}

The involvement of RNA silencing in plant-virus interactions is not a one-way street. Although the host plant uses RNA silencing to inhibit viral infection, our discovery of CMV Y-sat siRNA-directed host gene silencing suggests that viruses also use RNA silencing to impact the host genome. Viral siRNAs often accumulate to relatively high levels in infected tissues in comparison with endogenous sRNAs. As discussed earlier, these viral siRNAs have the potential to match host gene sequences either partially or completely and direct silencing of the host genes through mRNA degradation, translational repression, or DNA methylation. Therefore, it is possible that fortuitous silencing of host genes by virus-derived siRNAs is a widespread phenomenon. In this respect, single-nucleotide polymorphisms of the host genome could contribute to plant resistance to viral diseases, as demonstrated by the different Nicotiana spp. responding differently to CMV Y-sat-induced yellowing symptoms (Fig. 1C) (Smith et al. 2011). Consequently, nucleotide sequence variations in favor of host viral resistance may be positively selected for the host genome.

A major consequence of VSR function on host antiviral silencing is the interference of the host RNA silencing pathways. In addition to changes in genome-wide gene expression, recent studies suggest that this VSR effect could also result in both genetic and epigenetic modifications in the host genome. For instance, transgenic expression of VSR derived from germiniviruses results in genome-wide reduction of DNA methylation and transcriptional activation of transposons and transgenes (Buchmann et al. 2009). Similarly, infection of plants with a tobamovirus leads to a decrease in global genome methylation and promotes genetic rearrangements in systemic tissues (Kathiria et al. 2010; Yao et al. 2011). Increased transposon activity and genetic rearrangement can both cause genetic mutations in the host genome. In addition to genetic mutations, virus-induced changes in DNA methylation would alter the epigenetic status of the host genome, an effect that can be heritable. The effect of VSR or viral infection on host genome stability could be one reason why plant viruses usually are excluded from meristematic or germline cells because genetic and epigenetic mutations in these cells would likely be passed on to subsequent generations.

However, host genome changes caused by VSR or viral infection could also contribute positively to host genome evolution by increasing genetic and epigenetic diversities. In this respect, viruses are not just pathogenic but can also be regarded as a beneficial symbiot of plants. Virus-induced genetic and epigenetic changes could potentially be exploited for developing new crop varieties. Naturally occurring mutant buds ("sports") are often the source of new horticultural varieties, and the occurrence of these natural variants may well be the result of transposon-mediated genomic changes in somatic tissues in response to environmental stimuli. Therefore, deliberate infection of horticultural plants with viruses that express strong silencing sup- pressors could increase the frequency of sports and facilitate the breeding of new varieties. Regeneration of plants from virusinfected somatic tissues of other crop plants could also help to generate new populations of genetic and epigenetic variants with novel traits.

\section{CONCLUSION}

Viruses have been extensively studied ever since they were first identified over a century ago, and many technologies have been developed to prevent viral infection or combat viral diseases in animals and plants. Therefore, it is remarkable that very little is known about the molecular mechanisms of viral disease induction and host specificity of viral diseases. The understanding of RNA-silencing mechanisms over the last decade or so has opened up a new avenue for us to examine these critical questions. It has now become clear that RNA silencing plays a critical role in plant-virus interaction: viruses are both the inducer and target of RNA silencing, some of the key plant RNA-silencing machineries appear to function primarily in antiviral defense, and viruses have evolved various strategies to overcome these antiviral silencing mechanisms. Recent studies have indicated that viruses in animals are also subject to RNA-silencing-mediated resistance (Ding and Voinnett 2007), suggesting that RNA silencing may also play an important role in animal-virus interactions. However, it remains unknown whether RNA silencing plays a major role in determining the host specificity of virus infection. Most viruses in plants are transmitted through insect vectors and, for some of these viruses, an extended period inside the insect body is indispensable for successful infection of the host plants; the specific insect vector of a particular virus is often a major determinant of its natural host range. Therefore, in order to understand the role of RNA silencing in host specificity of viruses, it is important to investigate whether RNA silencing plays a role in the three-way interaction among viruses, insects, and host plants.

In this review, we have discussed several scenarios where RNA silencing might be involved in viral disease induction in plants (Fig. 3), including i) interference of host miRNA function and, hence, development by VSR; ii) suppression of naturally occurring host gene silencing by VSR; and iii) silencing of host genes directed by virus-derived sRNAs due to sequence homology. However, although evidence has become available to support these possible mechanisms in plants, further studies are needed to confirm whether they account for most of the plant virus symptoms or if alternative RNA-silencing-dependent or independent mechanisms are responsible for virus disease induction. Furthermore, while animal viruses are shown to encode VSR and encode sRNAs, it remains unclear if these viral VSR and sRNAs play a direct role in disease induction. The recent advance in RNA sequencing technologies will undoubtedly result in identification of new viral sRNAs and their potential host target genes in animals, which would help to answer the question as to whether viral sRNA-directed host gene silencing also plays a role in viral disease induction in animals. Further understanding of the functions of host sRNA pathways in gene regulation and disease development in animals would also help to understand the possible role of viral VSR in disease induction.

Plant viruses are often accompanied by small, "parasitic", subviral molecules, including satellites and defective interfering (DI) RNAs (Hu et al. 2009; Pathak and Nagy 2009), which depend on the associated virus for replication, encapsidation, and transmission. In most cases, the presence of these small subviral species attenuates the symptoms of the associated viruses. It has long been thought that such symptom attenuation is caused by the subviral species competing for viral replicase, reducing the 
replication of the associated virus. However, recent studies have implicated RNA-silencing mechanisms in satellite or DI RNAmediated symptom attenuation. For instance, a satellite RNA of CMV was shown to downregulate the expression of the $2 \mathrm{~b}$ VSR of CMV (Hou et al. 2011), suggesting that attenuation of CMVcaused symptoms by the satellite RNA may result from increased RNA silencing against CMV or reduced interference of endogenous sRNA function due to decreased expression of $2 b$. Also, it was shown that replication of DI RNAs of tombusvirus dramatically increases the level of virus-specific siRNAs, resulting in the saturation of the P19 VSR and the accumulation of unbound siRNAs (Havelda et al. 2005). The authors suggested that these unbound siRNAs have the potential to be loaded to RISC, inducing antiviral silencing and, hence, reducing the accumulation of the helper tombusvirus, resulting in reduced viral symptoms. Reduced symptoms could also be a result of diminished interference of host sRNA functions by P19 due to its saturation by DI siRNAs. It is interesting to note that animal viruses also have DI molecules (Pathak and Nagy 2009), and at least one animal virus (hepatitis B) is associated with a satellite (hepatitis D). Therefore, it would be interesting to examine whether these subviral species interact with VSR to modulate virus-induced symptoms in animals.

Our understanding of RNA-silencing mechanisms has provided a technical platform for developing new antiviral strategies in plants as well as in animals. Long hpRNA and artificial miRNA transgenes have been demonstrated to be effective at conferring resistance against RNA viruses in plants (Niu et al. 2006; Qu et al. 2007; Schwab et al. 2006; Wang and Waterhouse 2001). hpRNA transgenes targeting both the coding region (to induce RNA degradation) and the regulatory region (to induce DNA methylation) of DNA virus genomes could also be potentially used to engineer resistance against DNA viruses in plants. Similar RNAi-based approaches are also being exploited for preventing viral infections in animals, although issues such as how to effectively and safely deliver RNAi constructs to target tissues have yet to be resolved (DeVincenzo 2012). Further understanding of the role of RNA silencing in viral disease induction may allow us to develop alternative antiviral strategies. For instance, the expression of a silencing-resistant version of the CHLI gene, in which the nucleotide sequence targeted by the CMV Y-satellite siRNAs is modified to disrupt the homology and, hence, prevent silencing, completely blocked the development of the yellowing symptoms in tobacco (Fig. 1C) (Smith et al. 2011). Thus, technologies that can block viral sRNA-induced host gene silencing, such as expressing silencing-resistant target genes or inhibiting the function of viral sRNAs, could become an effective therapeutic for preventing viral sRNA-caused diseases. Introducing nucleic acid species that can sequester VSR functions could also be used to reduce virus symptoms.

\section{ACKNOWLEDGMENTS}

M.-B. Wang was supported by an Australian Research Council Future Fellowship (FT0991956).

\section{LITERATURE CITED}

Ahluwalia, J. K., Khan, S. Z., Soni, K., Rawat, P., Gupta, A., Hariharan, M., Scaria, V., Lalwani, M., Pillai, B., Mitra, D., and Brahmachari, S. K. 2008. Human cellular microRNA hsa-miR-29a interferes with viral nef protein expression and HIV-1 replication. Retrovirology 5:117.

Akbergenov, R., Si-Ammour, A., Blevins, T., Amin, I., Kutter, C. Vanderschuren, H., Zhang, P., Gruissem, W., Meins, F., Jr., Hohn, T., and Pooggin, M. M. 2006. Molecular characterization of geminivirus-derived small RNAs in different plant species. Nucleic Acids Res. 34:462-471.

Asaoka, R., Shimura, H., Arai, M., and Masuta, C. 2010. A progeny virus from a cucumovirus pseudorecombinant evolved to gain the ability to accumulate its RNA silencing suppressor leading to systemic infection in tobacco. Mol. Plant-Microbe Interact. 23:332-339.

Azevedo, J., Garcia, D., Pontier, D., Ohnesorge, S., Yu, A., Garcia, S., Braun, L., Bergdoll, M., Hakimi, M. A., Lagrange, T., and Voinnet, O. 2010. Argonaute quenching and global changes in Dicer homeostasis caused by a pathogen-encoded GW repeat protein. Genes Dev. 24:904915.

Baulcombe, D. 2004. RNA silencing in plants. Nature 431:356-363.

Baumberger, N., Tsai, C.-H., Lie, M., Havecker, E., and Baulcombe, D. C. 2007. The Polerovirus silencing suppressor P0 targets ARGONAUTE proteins for degradation. Curr. Biol. 17:1609-1614.

Blevins, T., Rajeswaran, R., Shivaprasad, P. V., Beknazariants, D., SiAmmour, A., Park, H. S., Vazquez, F., Robertson, D., Meins, F., Jr. Hohn, T., and Pooggin, M. M. 2006. Four plant Dicers mediate viral small RNA biogenesis and DNA virus induced silencing. Nucleic Acids Res. 34:6233-6246.

Blevins, T., Rajeswaran, R., Aregger, M., Borah, B. K., Schepetilnikov, M., Baerlocher, L., Farinelli, L., Meins, F., Jr., Hohn, T., and Pooggin, M. M. 2011. Massive production of small RNAs from a non-coding region of Cauliflower mosaic virus in plant defense and viral counterdefense. Nucleic Acids Res. 39:5003-5014.

Bortolamiol, D., Pazhouhandeh, M., Marrocco, K., Genschik, P., and Ziegler-Graff, V. 2007. The Polerovirus F Box protein P0 targets ARGONAUTE1 to suppress RNA silencing. Curr. Biol. 17:1615-1621.

Brodersen, P., Sakvarelidze-Achard, L., Bruun-Rasmussen, M., Dunoyer, P., Yamamoto, Y.Y., Sieburth, L., and Voinnet, O. 2008. Widespread translational inhibition by plant miRNAs and siRNAs. Science 320:1185-1190.

Buchmann, R. C., Asad, S., Wolf, J. N., Mohannath, G., and Bisaro, D. M. 2009. Geminivirus AL2 and L2 proteins suppress transcriptional gene silencing and cause genome-wide reductions in cytosine methylation. J. Virol. 83:5005-5013.

Burgyán, J., and Havelda, Z. 2011. Viral suppressors of RNA silencing. Trends Plant Sci. 16:265-272.

Carrington, J. C., and Ambros, V. 2003. Role of microRNAs in plant and animal development. Science 301:336-338.

Chapman, E. J., Prokhnevsky, A. L., Gopinath, K., Valerian, V. D., and Carrington, J. C. 2004. Viral RNA silencing suppressors inhibit the microRNA pathway at an intermediate step. Genes Dev. 18:1179-1186.

Chellappan, P., Vanitharani, R., and Fauquet, C. M. 2005. MicroRNAbinding viral protein interfere with Arabidopsis development. Proc. Natl. Acad. Sci. U.S.A. 102:10381-10386.

Choi, C.W., Qu, F., Ren, T., Ye, X., and Morris, T. J. 2004. RNA silencingsuppressor function of Turnip crinkle virus coat protein cannot be attributed to its interaction with the Arabidopsis protein TIP. J. Gen. Virol. 85:3415-3420

Cullen, B. R. 2009. Viral and cellular messenger RNA targets of viral microRNAs. Nature 457:421-425.

Dekker, E. L., Derks, F. L. M, Asjes, C. J., Lemmers, M. E. C., Bol, J. F., and Langeveld, S. A. 1993. Characterization of potyviruses from tulip and lily which cause flower-breaking. J. Gen. Virol. 74:881-887.

DeVincenzo, J. P. 2012. The promise, pitfalls and progress of RNA-interference-based antiviral therapy for respiratory viruses. Antivirus Ther. $17: 213-225$.

Diaz-Pendon, J. A., Li, F., Li, W.-X., and Ding, S.-W. 2007. Suppression of antiviral silencing by Cucumber mosaic virus $2 \mathrm{~b}$ protein in Arabidopsis is associated with drastically reduced accumulation of three classes of viral small interfering RNAs. Plant Cell 19:2053-2063.

Diermann, N., Matousek, J., Junge, M., Riesner, D., and Steger, G. 2010. Characterization of plant miRNAs and small RNAs derived from potato spindle tuber viroid (PSTVd) in infected tomato. Biol. Chem. 391:1379-1390.

Ding, S. W., and Voinnet, O. 2007. Antiviral immunity directed by small RNAs. Cell 130:413-426.

Donaire, L., Barajas, D., Martinez-Garcia, B., Martinez-Priego, L., Pagan, I., and Llave, C. 2008. Structural and genetic requirements for the biogenesis of Tobacco Rattle Virus-derived small interfering RNAs. J. Virol. 82:5167-5177.

Du, P., Wu, J., Zhang, J., Zhao, S., Zheng, H., Gao, G., Wei, L., and Li, Y. 2011. Viral infection induces expression of novel phased microRNAs from conserved cellular microRNA precursors. PLoS Pathog. 7:e1002176. Published online.

Duan, C. G., Fang, Y. Y., Zhou, B. J., Zhao, J. H., Hou, W. N., Zhu, H., Ding, S. W., and Guo, H. S. 2012. Suppression of Arabidopsis ARGONAUTE1-mediated slicing, transgene-induced RNA silencing, and DNA methylation by distinct domains of the Cucumber mosaic virus $2 \mathrm{~b}$ protein. Plant Cell 24:259-274.

Eamens, A. L., Wang, M.-B., Smith, N. A., and Waterhouse, P. M. 2008. RNA silencing in plants: Yesterday, today and tomorrow. Plant Physiol. 147:456-468 
Ebhardt, H. A., Thi, E. P., Wang, M. B., and Unrau, P. J. 2005. Extensive 3' modification of plant small RNAs is modulated by helper componentproteinase expression. Proc. Natl. Acad. Sci. U.S.A. 102:13398-13403.

Garcia-Ruiz, H., Takeda, A., Chapman, E. J., Sullivan, C. M., Fahlgren, N., Brempelis, K. J., and Carrington, J. C. 2010. Arabidopsis RNA-dependent RNA polymerases and dicer-like proteins in antiviral defense and small interfering RNA biogenesis during Turnip mosaic virus infection. Plant Cell 22:481-496.

Gómez, G., Martínez, G., and Pallás, V. 2008. Viroid-induced symptoms in Nicotiana benthamiana plants are dependent on RDR6 activity. Plant Physiol. 148:414-423.

Gottwein, E., and Cullen, B. R. 2008. Viral and cellular microRNAs as determinants of viral pathogenesis and immunity. Cell Host Microbe 3:375-387.

Gottwein, E., Mukherjee, N., Sachse, C., Frenzel, C., Majoros, W. H., Chi, J.-T. A., Braich, R., Manoharan, M., Soutschek, J., Ohler, U., and Cullen, B.R. 2007. A viral microRNA functions as an orthologue of cellular miR-155. Nature 450:1096-1101.

Grey, F., Tirabassi, R., Meyers, H., Wu, G., McWeeney, S., Hook, L., and Nelson, J.A., 2010. Aviral microRNA down-regulates multiple cell cycle genes through mRNA 5' UTRs. PLoS Pathog. 6:e1000967. Published online.

Grundhoff, A., and Sullivan, C. S. 2011. Virus-encoded microRNAs. Virology 411:325-343.

Haag, J. R., and Pikaard, C. S. 2011. Multisubunit RNA polymerases IV and V: Purveyors of non-coding RNA for plant gene silencing. Nat. Rev. Mol. Cell. Biol. 12:483-492.

Haas, G., Azevedo, J., Moissiard, G., Geldreich, A., Himber, C., Bureau, M., Fukuhara, T., Keller, M., and Voinnet, O. 2008. Nuclear import of CaMV P6 is required for infection and suppression of the RNA silencing factor DRB4. EMBO (Eur. Mol. Biol. Organ.) J. 27:2102-2112.

Harvey, J. J., Lewsey, M. G., Patel, K., Westwood, J., Heimstädt, S., Carr, J. P., and Baulcombe, D. C. 2011. An antiviral defense role of AGO2 in plants. PLoS One 6:e14639.Published online.

Havelda, Z., Hornyik, C., Válóczi, A., and Burgyán, J. 2005. Defective interfering RNA hinders the activity of a tombusvirus-encoded posttranscriptional gene silencing suppressor. J. Virol. 79:450-457.

Hirai, K., Kubota, K., Mochizuki, T., Tsuda, S., and Meshi, T. 2008. Antiviral RNA silencing is restricted to the marginal region of the dark green tissue in the mosaic leaves of Tomato mosaic virus-infected tobacco plants. J. Virol. 82:3250-3260.

Hohn, T., and Vazquez, F. 2011. RNA silencing pathways of plants: Silencing and its suppression by plant DNA viruses. Biochim. Biophys. 1809:588-600.

Hou, W. N., Duan, C. G., Fang, R. X., Zhou, X. Y., and Guo, H. S. 2011 Satellite RNA reduces expression of the $2 \mathrm{~b}$ suppressor protein resulting in the attenuation of symptoms caused by Cucumber mosaic virus infection. Mol. Plant Pathol. 12:595-605.

Hu, C. C., Hsu, Y. H., and Lin, N. S. 2009. Satellite RNAs and satellite viruses of plants. Viruses 1:1325-1350.

Hull, R. 2002. Pages 47-74 in: Mathews' Plant Virology, 4th ed. Academic Press, San Diego, CA, U.S.A.

Inaba, J., Kim, B. M., Shimura, H., and Masuta, C. 2011. Virus-induced necrosis is a consequence of direct protein-protein interaction between a viral RNA-silencing suppressor and a host catalase. Plant Physiol. 156:2026-2036

Ishibashi, K., Nishikiori, M., and Ishikawa, M. 2010. Interactions between tobamovirus replication proteins and cellular factors: Their impacts on virus multiplication. Mol. Plant-Microbe Interact. 23:1413-1419.

Itaya, A., Zhong, X., Bundschuh, R., Qi, Y., Wang, Y, Takeda, R., Harris, A. R., Molina, C., Nelson, R. S., and Ding, B. 2007. A structured viroid RNA serves as a substrate for Dicer-like cleavage to produce biologically active small RNAs but is resistant to RNA-induced silencing complex-mediated degradation. J. Virol. 81:2980-2994.

Jaubert, M. Bhattacharjee, S., Mello, A. F., Perry, K. L., and Moffett, P. 2011. ARGONAUTE2 mediates RNA-silencing antiviral defenses against Potato virus X in Arabidopsis. Plant Physiol. 156:1556-1564.

Jay, F., Wang, Y., Yu, A., Taconnat, L., Pelletier, S., Colot, V., Renou, J. P., and Voinnet, O. 2011. Misregulation of AUXIN RESPONSE FACTOR 8 underlies the developmental abnormalities caused by three distinct viral silencing suppressors in Arabidopsis. PLoS Pathog. 7:e1002035. Published online.

Jenner, C. E., Wang, X., Tomimura, K., Ohshima, K., Ponz, F., and Walsh, J. A. 2003. The dual role of the potyvirus P3 protein of Turnip mosaic virus as a symptom and avirulence determinant in brassicas. Mol. PlantMicrobe Interact. 16:777-784

Ji, L. H., and Ding, S. W. 2001. The suppressor of transgene RNA silencing encoded by Cucumber mosaic virus interferes with salicylic acidmediated virus resistance. Mol. Plant-Microbe Interact. 14:715-724.

Jopling, C. L., Yi, M., Lancaster, A. M., Lemon, S. M., and Sarnow, P.
2005. Modulation of hepatitis $\mathrm{C}$ virus RNA abundance by a liver-specific microRNA. Science 309:1577-1581.

Kaneko, Y., Inukai, T, Suehiro, N., Natsuaki, T., and Masuta, C. 2004. Fine genetic mapping of the TuNI locus causing systemic veinal necrosis by Turnip mosaic virus infection in Arabidopsis thaliana. Theor. Appl. Genet. 110:33-40.

Kasschau, K. D., Xie, Z., Allen, E., Llave, C., Chapman, E. J., Krizan, K. A., and Carrington, J. C. 2003. P1/HC-Pro, a viral suppressor of RNA silencing, interfere with Arabidopsis development and miRNA function. Dev. Cell 4:205-217.

Kathiria, P., Sidler, C., Golubov, A., Kalischuk, M., Kawchuk, L. M., and Kovalchuk, I. 2010. Tobacco mosaic virus infection results in an increase in recombination frequency and resistance to viral, bacterial, and fungal pathogens in the progeny of infected tobacco plants. Plant Physiol. 153:1859-1870.

Koseki, M., Goto, K., Masuta, C., and Kanazawa, A. 2005. The star-type color pattern in Petunia hybrida "Red Star" flowers is induced by sequence-specific degradation of chalcone synthase RNA. Plant Cell Physiol. 46:1879-1883.

Lakatos, L., Csorba, T., Pantaleo, V., Chapman, E. J., Carrington, J. C., Liu, Y. P., Dolja, V. V., Calvino, L. F., López-Moya, J. J., and Burgyán, J. 2006. Small RNA binding is a common strategy to suppress RNA silencing by several viral suppressors. EMBO (Eur. Mol. Biol. Organ.) J. 25:2768-2780

Lecellier, C. H., Dunoyer, P., Arar, K., Lehmann-Che, J., Eyquem, S., Himber, C., Saïb, A., and Voinnet, O. 2005. A cellular microRNA mediates antiviral defense in human cells. Science 308:557-560.

Lindbo, J. A., Silva-Rosales, L., Proebsting, W. M., and Dougherty, W. G. 1993. Induction of a highly specific antiviral state in transgenic plants: Implications for regulation of gene expression and virus resistance. Plant Cell 5:1749-1759.

Lozsa, R., Csorba, T., Lakatos, L., and Burgyan, J. 2008. Inhibition of 3' modification of small RNAs in virus-infected plants require spatial and temporal co-expression of small RNAs and viral silencing-suppressor proteins. Nucleic Acids Res. 36:4099-4107.

Matzke, M., Kanno, T., Daxinger, L., Huettel, B., and Matzke, A. J. 2009. RNA-mediated chromatin-based silencing in plants. Curr. Opin. Cell Biol. 21:367-376.

Maule, A. J., Caranta, C., and Boulton, M. I. 2007. Sources of natural resistance to plant viruses: Status and prospects. Mol. Plant Pathol. 8:223-231.

Meister, G., and Tuschl, T. 2004. Mechanisms of gene silencing by double-stranded RNA. Nature 431:343-349.

Mérai, Z., Kerényi, Z., Kertész, S., Magna, M., Lakatos, L., and Silhavy, D. 2006. Double-stranded RNA binding may be a general plant RNA viral strategy to suppress RNA silencing. J. Virol. 80:5747-5756.

Moissiard, G., and Voinnet, O. 2006. RNA silencing of host transcripts by Cauliflower mosaic virus requires coordinated action of the four Arabidopsis Dicer-like proteins. Proc. Natl. Acad. Sci. U.S.A. 103:19593 19598

Molnár, A., Csorba, T., Lakatos, L., Várallyay, E., Lacomme, C., and Burgyán, J. 2005. Plant virus-derived small interfering RNAs originate predominantly from highly structured single-stranded viral RNAs. J. Virol. 79:7812-7818.

Moore, C. J., Sutherland, P. W., Forster, R. L., Gardner, R. C., and MacDiarmid, R. M. 2001. Dark green islands in plant virus infection are the result of posttranscriptional gene silencing. Mol. Plant-Microbe Interact. 14:939-946.

Niu, Q.-W., Lin, S.-S., Reyes, J. L., Chen, K.-C., Wu, H.-W., Yeh, S.-D., and Chua, N. H. 2006. Expression of artificial microRNAs in transgenic Arabidopsis thaliana confers virus resistance. Nat. Biotechnol. 24:1420-1428.

Pallas, V., and Garcia, A. 2011. How do plant viruses induce diseases? Interactions and interference with host components. J. Gen. Virol 92:2691-2705

Pasquinelli, A. E., and Ruvkun, G. 2002. Control of developmental timing by micrornas and their targets. Annu. Rev. Cell Dev. Biol. 18:495-513.

Pathak, K. B., and Nagy, P. D. 2009. Defective interfering RNAs: Foes of viruses and friends of virologists. Viruses 1:895-919.

Perez-Quintero, A., Neme, R., Zapata, A., and Lopez, C. 2010. Plant microRNAs and their role in defense against viruses: A bioinformatics approach. BMC Plant Biol. 10:138.

Pignatta, L. F., Bendiz, C., Brunkard, J. O., Cohn, M. M., Tung, J., Sun, H., Kumar, P., and Baker, B. 2012. MicroRNA regulation of plan innate immune receptors. Proc. Natl. Acad. Sci. U.S.A. 109:1790-1795.

Qi, S., Bao, F. S., and Xie, Z. 2009. Samll RNA deep sequencing reveals role for Arabidopsis thaliana RNA-dependent RNA polymerases in viral siRNA biogenesis. PLoS One 4:e 4971. Published online.

Qu, F. 2010. Antiviral role of plant-encoded RNA-dependent RNA polymerases revisited with deep sequencing of small interfering RNAs of 
virus origin. Mol. Plant-Microbe Interact. 23:1248-1252.

Qu, F., Ye, X., and Morris, T. J. 2008. Arabidopsis DRB4, AGO1, AGO7, and RDR6 participate in a DCL4-initiated antiviral RNA silencing pathway negatively regulated by DCL1. Proc. Natl. Acad. Sci. U.S.A. 105:14732-14737.

Qu, J., Ye, J., and Fang, R. 2007. Artificial microRNA-mediated virus resistance in plants. J. Virol. 81:6690-6699.

Raja, P., Sanville, B. C., Buchmann, R. C., and Bisaro, D. M. 2008. Viral genome methylation as an epigenetic defense against geminiviruses. J. Virol. 82:8997-9007.

Rodríguez-Negrete, E. A., Carrillo-Tripp, J., and Rivera-Bustamante, R. F. 2009. RNA silencing against geminivirus: Complementary action of posttranscriptional gene silencing and transcriptional gene silencing in host recovery. J. Virol. 83:1332-1340.

Roth, B. M., Pruss, G. J., and Vance, V. B. 2004. Plant viral suppressors of RNA silencing. Virus Res. 102:97-108.

Ruiz-Ferrer, V., and Voinnet, O. 2009. Role of plant small RNAs in biotic stress responses. Annu. Rev. Plant Biol. 60:485-510.

Saunders, K., Bedford, I. D., Yahara, T., and Bedford, I. D. 2003. The earliest recorded plant virus disease. Nature 422:831.

Schwab, R., Ossowski, S., Riester, M., Warthmann, N., and Weigel, D. 2006. Highly specific gene silencing by artificial microRNAs in Arabidopsis. Plant Cell 18:1121-1133.

Senda, M., Masuta, C., Ohnishi, S., Goto, K., Kasai, A., Sano, T., Hong, J.-S., and MacFarlane, S. 2004. Patterning of virus-infected Glycine max seed coat is associated with suppression of endogenous silencing of chalcone synthase genes. Plant Cell 16:807-818.

Shams-Bakhsh, M., Canto, M., and Palukaitis, P. 2007. Enhanced resistance and neutralization of defense responses by suppressors of RNA silencing. Virus Res. 130:103-109.

Shi, B. J., Symons, R. H., and Palukaitis, P. 2008. The cucumovirus 2b gene drives selection of inter-viral recombinations affecting the crossover site, the acceptor RNA and the rate of selection. Nucleic Acids Res. 36:1057-1071.

Shimura, H., Pantaleo, V., Ishihara, T., Myojo, N., Inaba, J., Sueda, K., Burgyán, J., and Masuta, C. 2011. A viral satellite RNA induces yellow symptoms on tobacco by targeting a gene involved in chlorophyll biosynthesis using the RNA silencing machinery. PLoS Pathog. 7:e1002021. Published online.

Smith, N. A., Eamens, A. L., and Wang, M. B. 2011. Viral small interfering RNAs target host genes to mediate disease symptoms in plants. PLoS Pathog. 7:e1002022. Published online.

Stern-Ginossar, N., Elefant, N., Zimmermann, A., Wolf, D. G., Saleh, N. Biton, M., Horwitz, E., Prokocimer, Z., Prichard, M., Hahn, G., GoldmanWohl, D., Greenfield, C., Yagel, S., Hengel, H., Altuvia, Y., Margalit, H., and Mandelboim, O. 2007. Host immune system gene targeting by a viral miRNA. Science 317:376-381.

Sullivan, C. S., Grundhoff, A. T., Tevethia, S., Pipas, J. M., and Ganem, D. 2005. SV40-encoded microRNAs regulate viral gene expression and reduce susceptibility to cytotoxic T cells. Nature 435:682-686.

Szittya, G., Molnár, A., Silhavy, D., Hornyik, C., and Burgyán, J. 2002. Short defective interfering RNAs of tombusviruses are not targeted but trigger post-transcriptional gene silencing against their helper virus. Plant Cell 14:359-372.

Várallyay, E. Válóczi, A., Agyi, A., Burgyán, J., and Havelda, Z. 2010. Plant virus-mediated induction of miR168 is associated with repression of ARGONAUTE1 accumulation. EMBO (Eur. Mol. Biol. Organ.) J. 29:3507-3519.

Voinnet, O. 2005. Induction and suppression of RNA silencing: Insights from viral infections. Nat. Rev. Genet. 6:206-220.

Wang, M. B., and Metzlaff, M. 2005. RNA silencing and antiviral defense in plants. Curr. Opin. Plant Biol. 8:216-222.

Wang, M. B., and Waterhouse, P. M. 2001. Applications of gene silencing in plants. Curr. Opin. Plant Biol. 5:146-150.

Wang, M.-B., Bian, X.-Y., Wu, L.-M., Liu, L.-X., Smith, N. A., Isenegger, D., Wu, R.-M., Masuta, C., Vance, V. B., Watson, J. M., Rezaian, A. Dennis, E. S., and Waterhouse, P. M. 2004. On the role of RNA silencing in the pathogenicity and evolution of viroids and viral satellites. Proc. Natl. Acad. Sci. U.S.A. 101:3275-3280.

Wang, X. B., Wu, Q., Ito, T., Cillo, F., Li, W. X., Chen, X., Yu, J. L., and Ding, S. W. 2010. RNAi-mediated viral immunity requires amplification of virus-derived siRNAs in Arabidopsis thaliana. Proc. Natl. Acad. Sci. U.S.A. 107:484-489.

Wang, X. B., Jovel, J., Udomporn, P., Wang, Y., Wu, Q., Li, W. X., Gasciolli, V., Vaucheret, H., and Ding, S. W. 2011. The 21-nucleotide, but not 22nucleotide, viral secondary small interfering RNAs direct potent antiviral defense by two cooperative argonautes in Arabidopsis thaliana. Plant Cell 23:1625-1638.

Wassenegger, M., Heimes, S., Riedel, L., and Sanger, H. L. 1994. RNAdirected de novo methylation of genomic sequences in plants. Cell 76:567-576.

Waterhouse, P. M., Wang, M. B., and Lough, T. 2001. Gene silencing as an adaptive defense against viruses. Nature 411:834-842.

Whitham, S., Dinesh-Kumar, S. P., Choi, D., Hehl, R., Corr, C., and Baker, B. 1994. The product of the tobacco mosaic virus resistance gene $\mathrm{N}$ : Similarity to toll and the interleukin-1 receptor. Cell 78:1101-1115.

Yadav, R. K., and Chattopadhyay, D. 2011. Enhanced viral intergenic region-specific short interfering RNA accumulation and DNA methylation correlates with resistance against a geminivirus. Mol. Plant-Microbe Interact. 24:1189-1197

Yang, X., Xie, Y., Raja, P., Li, S., Wolf, J. N., Shen, Q., Bisaro, D. M., and Zhou, X. 2011. Suppression of methylation-mediated transcriptional gene silencing by $\beta \mathrm{C} 1-\mathrm{SAHH}$ protein interaction during geminivirusbetasatellite infection. PLoS Pathog. 7:e1002329. Published online.

Yao, Y., Bilichak, A., Golubov, A., and Kovalchuk, I. 2011. Local infection with oilseed rape mosaic virus promotes genetic rearrangements in systemic Arabidopsis tissue. Mutat. Res. 709-710:7-14.

Ying, X. B., Dong, L., Zhu, H., Duan, C. G., Du, Q. S., Lv, D. Q., Fang, Y. Y., Garcia, J. A., Fang, R. X., and Guo, H. S. 2010. RNA-dependent RNA polymerase 1 from Nicotiana tabacum suppresses RNA silencing and enhances viral infection in Nicotiana benthamiana. Plant Cell 22:1358-1372.

Yu, B., Chapman, E. J., Yang, Z., Carrington, J. C., and Chen, X. 2006. Transgenically expressed viral RNA silencing suppressors interfere with microRNA methylation in Arabidopsis. FEBS (Fed. Eur. Biochem. Soc.) Lett. 580:3117-3120.

Zhai, J., Jeong, D. H., De Paoli, E., Park, S., Rosen, B. D., Li, Y., Gonzalez, A. J., Yan, Z., Kitto, S. L., Grusak, M. A., Jackson, S. A., Staey, G., Cook, D. R., Green, P. J., Sherrier, D. J., and Meyers, B. C. 2011. MicroRNAs as master regulators of the plant NB-LRR defense gene family via the production of phased, trans-acting siRNAs. Genes Dev. 25:2540-2553.

Zhang, W., Gao, S., Zhou, X., Xia, J., Chellappan, P., Zhou, X., Zhang, X., and Jin, H. 2010. Multiple distinct small RNAs originated from the same microRNA precursors. Genome Biol. 11:R81.

Zhang, X., Yuan, Y.-R., Pei, Y., Lin, S.-S., Tuschl, T., Patel, D. J., and Chua, N. H. 2006. Cucumber mosaic virus-encoded 2b suppressor inhibits Arabidopsis Argonaute1 cleavage activity to counter plant defense. Genes Dev. 20:3255-3268.

Zhang, Z., Chen, H., Huang, X., Xia, R., Zhao, Q., Lai, J., Teng, K., Li, Y., Liang, L., Du, Q., Zhou, X., Guo, H., and Xie, Q. 2011. BSCTV C2 attenuates the degradation of SAMDC1 to suppress DNA methylationmediated gene silencing in Arabidopsis. Plant Cell 23:273-288.

Zhu, S., Gao, F., Cao, X., Chen, M., Ye, G., Wei, C., and Li, Y. 2005. The Rice dwarf virus $\mathrm{P} 2$ protein interacts with ent-kaurene oxidases in vivo, leading to reduced biosynthesis of gibberellins and rice dwarf symptoms. Plant Physiol. 139:1935-1945. 